\title{
The Limitations, Conditions, and Possibilities of Educational Research
}

\author{
Donald K. Sharpes \\ Arizona State University, Tempe, USA; \\ Cambridge University, Cambridge, UK
}

\begin{abstract}
This short essay reports on how limiting and narrow much of educational research is, how often its conclusions rarely apply to teachers, how it often uses statistics to camouflage inferior logic and clarity, and how interdisciplinary and contextual it can be if it broadens its perspetives. The slow trend to include studies from the neurosciences and the physical aspects of cognitive functioning into educational and psychological research studies is encouraging. The combined use of a variety of perspectives is promoted. As the title suggests, this report has three sections: 1 . What teacher education research is not, its limitations; 2 . What it is, its conditions; and 3. What it can be, its possibilities. The main purpose of this paper is to encourage more interdisciplinary, broadly-based educational research and to motivate researchers to explore developments in related fields.
\end{abstract}

Keywords: educational research, interdisciplinary, methodology, social sciences, knowledge integration, neurosciences

\section{Introduction}

A large body of research in education has multiple limitations, primarily because researchers do not always have their conclusions applicable to actual teaching situations and do not, in the popular phraseology of the day, think outside the box. Hence, the condition and state of educational research is often insular. The expansion of research studies needs to broaden its perspectives and integrate knowledge from a variety of other social science studies to achieve more relevant understandings. Such studies can add depth to the intellectual analysis of education and still be applicable to curricular content.

\section{What Educational Research Is Not, Its Limitations}

One way to begin to investigate what research is not is to start with the questions that have obsessed educational researchers and policy-makers for the past half century.

Why has not educational research yielded dramatic results in school practice as research has, for example, in medicine?

Why has educational research been avoided by other social and behavioral scientists and scorned by most of the academic community?

Why has educational research been isolated from schools and denigrated by teachers as having little value?

Donald K. Sharpes, Ph.D., professor, Emeritus College, Arizona State University; senior visiting fellow, Cambridge University. 
Answers to these questions can come from multiple perspectives. But there are at least four reasons educational research has become insular:

1. Educational researchers are too narrow in their views and methods;

2. They have criticized schools;

3. They have instituted a professionalism which shielded them from criticism while protecting narrow self-interests;

4. They have failed to conceptualize broadly.

A few remarks about each of these perspectives will be explored next.

\section{Research Is too Narrow in Views and Methodology}

Despite advanced technology and precision in measuring observations, elaborate quantitative measures can be used still to support an illogical or unreasonable premise. Some researchers tend to assume that because they use the certainty of mathematical methods that therefore conclusions deduced have a corresponding and convincing certainty. The precision of mathematics and statistics cannot overcome the imperfections of careless thought, hypotheses, experimentation, or analysis.

The invention of new technologies - the telescope, microscope, thermometer, and the electron microscope - all enlarged the scope of observation about the natural world. Precision in measurement became linked to new levels of observation in the natural and physical sciences. To gain legitimacy and professional recognition, the social sciences adopted mathematics as its primary investigative tool.

As a contrast, statistics help researchers find new uniformities among people and their actions, while artists find variation within individuals. Some educational researchers, resisting the orthodoxy of quantification, rely on qualitative data that they believe humanize the research experience. But there are limits. Postmodern researchers, for example, uniformly opposed to empiricism, use poetry and personal narrative to express truths about schooling to the detriment of scientific verification that can add more depth to an analysis.

Data from the social sciences help define the public experience, while literature and art help define personal realities and the imagination. Educational research has a love affair with methodology to the neglect of active and dynamic premises for its central purposes, like a consistent or engaging theoretical base.

\section{Researchers too Often Criticize Schools}

After a compulsion and penchant for methodology, the second reason educational research is often unsatisfactory is that research presumptuously and repeatedly tell us what works and what does not in schools, and then often concludes by denouncing the culture of the school. Social scientists have abandoned responsibility towards public education, but, following public opinion has been in the forefront of criticism of schools. The mandarins of the research establishment argue over methodology, diminished government and private funding, and the timidity of the schools to adopt their research findings, but little about altering their premises and precepts.

\section{Professional Self-interests}

The third reason educational research has not been widely accepted is the self-interests of the research profession. Research results do not easily enter into schooling practice. Educational researchers do not speak to teachers when they write their research reports. They usually only address other researchers. This is not true of other fields and practices, for example, engineering or medicine. Consequently, schools have little incentive to adopt the practices research results advocate and prescribe. 
It is well known that the estrangement of research in educational practice is further complicated, because school teachers rarely conduct research on their own instruction or teaching. Formal educational research is mostly conducted by faculty in colleges and universities, and school people do not believe that researchers understand their problems well. Similarly, researchers in education are considered somewhat irrelevant to what happens in schools. The flow of educational research often assumes a strategy of looking at just one single criterion, such as teaching effectiveness, rather than at multiple variables, more difficult to control.

\section{Failure to Conceptualize Broadly}

Fourthly, what educational research has failed to do is broadening and deepening its theory and practice to capitalize on research based in other disciplines. Educational research has neglected interdisciplinary and a cross-disciplinary convergence of theories and methods (Cromer, 1997). A failure to incorporate the latest finding from the neurosciences is just one example of how limiting some research about schooling can be. Adding brain studies should be an integral component of all investigations in cognitive functioning.

Research investigators, because they largely focus on learning within an academic subject, rarely investigate abilities, skills, and aptitudes in a non-schooling environment. Educational researchers and polls have looked too closely at idealized perceptions of academic achievement, and assumed school performance relates to job performance. Sternberg (1997) argued that thinking and learning styles are often in conflict with each other and with job performance. He believed that the results of school grades, aptitude, and achievement tests in school performance may often mask real ability in life and job situations. Job performance may be demonstrated by an individual who makes adjustments to institutional or business thinking skills, an ability rarely linked to school performance measures or revealed by academic aptitude tests.

\section{What Research Is: An Adventure With a History}

Educational research is an adventure with a history of changing ideologies.

Research may be said to be partly art, but it is still all science. Research is both an activity and a state of mind. A beginning researcher experiences the frustration of combining the art of deciding on a line of inquiry with the application of an appropriate scientific methodology. Often, discoveries are made by re-analyzing old data, and by investigating and re-arranging the evidence and fitting it into a new perspective. The discovery is made first and always in the mind of the researcher.

The mind becomes receptive to novelty, the unexpected, and the attempt to reach into nature and extract one of the secrets, to see patterns in behavior no else has seen. Then, the object or behavior is drawn into the working consciousness of the researcher. Reflection occurs, and hypotheses are assembled and tested. Suddenly, there is a pulse of excitement about the possibility of finding a new truth. Perhaps a new image helps to coalesce the idea. All this is similar to the excitement of an artist, creating what did not exist before.

Logic and reason are the tools of the researcher. Logic seeks truth through reasoning, interpersonal dialogue, and argumentation. Science obtains results from observation and experimentation. So ingrained is the idea of verification of objective reality, an idea passed on from the Enlightenment, and because the mind has illusions and senses that can deceive us. The empirical and scientific formula has been the only methodology fully legitimized and adopted as providing the the best evidence.

Researchers who accept the guiding principles of philosophy and the cognitive sciences believe in the premises of human nature and the construct of mind. Those, on the other hand, who believe more in the 
physiological bases accept the brain and the neurosciences as their precepts and governing laws. But it is also possible to believe that, though there may be laws governing human actions, these laws defy the collective powers of calculation.

The researcher's goal is to find out why something works or does not work, and what rules or principles lay behind its purpose. It is not any easier to discover how people learn and how they come to know something than it is to discover rules of physics. But researchers are making more strides in uncovering the laws of physical nature, especially the neurosciences, than the laws of human nature. Sometimes, scientific findings contradict perceptions of what is real. Advances in the medical sciences demonstrate how far humanity has come in learning about how the body functions, about advances in theoretical astrophysics, and about what the universe is, its origin and its age. Theories of development have expanded the vision of human growth and discoveries in the neurosciences and in comprehension of the intricacies of cellular life.

But secondly, the history of research in education in the 21 st century is a chronicle of attempts at establishing validity and acceptance and a story of changing ideologies. Despite the efforts of countless dedicated researchers in education, some research direction has been dictated by the shifting ideologies of the day, as well as by the political vagaries of government and philanthropic funding sources.

\section{What Research Can Be: Knowledge Integration}

The search for scientific discoveries is for cures from diseases, like cancer and Ebola, the ultimate particles of matter, the composition of the surface of planets, and the stuff of stars. Research in all fields of inquiry is more than an intellectual exercise. Results can enlarge knowledge of the world, improve lives, and, in education, make instruction more efficient and be more appropriate to learning needs and overall human development.

Yet, research is only one method of human problem-solving. Its peculiar techniques vary from discipline to discipline. In educational research, there are only hesitant attempts to mingle techniques from a variety of academic pursuits: from political science, sociology, anthropology, as well as psychology and the neurosciences. The intellectual boundaries of certain sciences have become blurred, and no researcher can ignore developments in related disciplines as the disciplines themselves continuously evolve from differing centers to widening peripheries. The research mentality is more important than simply knowing the methodological mechanics for conducting a study.

Linking hypotheses to multiple, overlapping theories-for example, from Maslow's hierarchy in the affective domain, from personality theories of development, and from the cognitive and neurocognitive sciences - can be more persuasive, and integrate knowledge better than linking hypotheses to just one theory or from one sub-specialty.

Edmund Wilson in his 1988 book Consilience: The Unity of Knowledge linked facts and theories across disciplines in order to create a common ground for explanation (Wilson, 1988b). Linking the sciences and humanities is a great intellectual challenge of the mind. The frustration experienced in not seeing more attempts made towards that unity is caused more by academic artifacts than by creative and intellectual vigor.

Similarly, Best (1998) reported in her book, We've All Got Scars, a unifying methodology, an example of multidisciplinary research that reaches beyond the confines of the classroom. She observed the same class of students over four years. Her study went beyond the formal curriculum to explore the social world students create for themselves, how girls become second-class citizens and how boys' behavior is affected by male 
peer-group dynamics, and the expectations that they live up to male roles they are unprepared to meet.

Another example of a more recent application of a theory is that of culture, though it is often a misapplication of a term removed from its social science base in anthropology and used to clarify ethnicity. Giambattista Vico (1667-1744) is the inventor of the social sciences and the study of culture. He was the originator of a new methodology in the social sciences by recommending that researchers enter into the study of history and the myths and languages of other cultures. He believed that culture gave meaning to how people actually lived, an understanding of motives, fears, loves and hates, and hopes and ambitions. He rejected the methodology of mathematics as an inflexible tool for studying the complexity and variability of human affairs.

Vico is the first theorist to reject the reason of the Enlightenment and the rational criticism of Descartes, and to propose that myth, languages, and mores are more relevant in illuminating human nature, ideas James Joyce pursued in his novels, and Joseph Campbell in narrative explanations about the power of myth.

Similarly, the neurosciences is a fertile and burgeoning field of psychological inquiry and yet has been nearly totally neglected by the educational research establishment. At a time when even alternative medicinal practices are thriving, educational research seems to be stuck in an ossified past and out of step with developments in related fields.

Another fertile but neglected area by educational researchers is the relationship between the mind, the brain, behavior, and the central nervous system, even the physical health of the individual. Non-educational researchers discovered nearly two decades ago that there was a direct relationship between psychological stress and the blunting of the immune system, for example, during the preparation and taking of exams.

Lastly, unpopular but bold research conclusions, like Art Jensen's views on intelligence and race based, or Wilson's (1975) book Sociobiology, or Hernnstein and Murray's (1996) The Bell Curve, have met with especially vitriolic and personal attacks. Science and morality are separate realms of thought whose premises are never likely to be reconciled, as the clients of research resist conclusions when they conflict with strongly-held views of the world.

The social sciences have always vied for the nebulous territory between theology, and perhaps the humanities and the physical sciences. Francis Bacon, Descartes, and Condorcet gave us a taste for unbridled free scientific inquiry. Today, the postmodern agenda challenges the very foundations of verifiable science with personal visions, group experiences, and narrative self-cartharsis. Yet, society's major problems - poverty, overpopulation, environmental degradation, ethnic violence, racial enmity and discord, the arms escalation, to name a few - can only be solved through interdisciplinary knowledge integration.

One conclusion from a study of great researchers and from the minds of those who have significantly advanced the cause of civilization and learning is that even great minds are often ignorant of the processes under observation, as Marie Curie was initially of the effects of uranium, or those who have been pursuing the illusive neutrino particle. Many candidly admit that they are unsure of what they are looking for, or where it might be. Some scientists may not recognize in their lifetimes how their research findings will contribute to the betterment of mankind, or be part of a new breakthrough in knowledge. But everyone can realize how confrontation with great ideas can change one's personal life.

\section{Conclusion}

Educational research has its limitations. It is not just methodology, but logic and reasoning that should prevail in the conduct of inquiry. It is only scrupulous examination of all the evidence and a critical integration 
of existing knowledge, that absurd, commonplace, and implausible hypotheses can be rejected and new ones established. Integrating an accumulation of information requires more than the formation of hypotheses for verification. It also requires a creative imagination, an intuitive vision of the world where data do not remain lifeless but are heroic elements in the quest to understand all or parts of the human drama, not just life in schooling.

Such research has a history of a quest for justification and recognition among both the academic community and the general public. It should have a broader vision and more thoughtful purposes for its activities that incorporates a full range of the human intellectual experience. Researchers should be creators of knowledge, not merely compilers of data. Moreover, though the scholar may have an affectionate kinship with the country of birth or residence, such a scholar belongs to the community of scholars that knows no frontiers, no political prejudices, no hatreds, no racial discrimination, and no religious animosity.

Educational research has possibilities if it broadens its approach to include all facets of human existence, not just the artificial life of the schooling establishment, or the limitations of the cognitive sciences. It is clarity of mind, singularity of purpose, and dedication to relevant goals that should motivate future efforts.

Kuhn's (1970) pioneering work in the history of science noted that the discovery of something is not as important as the change in thinking required to accept it, first in the scientific community, and then throughout the global community. The goal of all teaching and research, indeed the goal of all education, is to bring about such a new mind-set, to understand the limitations, conditions, and possibilities of science, and to perceive a different and broader way of looking at the world.

\section{References}

Asimov, I. (1959). Breakthroughs in science. New York, N.Y.: Scholastic Books.

Babbie, E. R. (1979). The practice of social research. Belmont, C.A.: Wadsworth.

Bergin, T. G., \& Fisch, M. H. (1988/1948). The new science of Giambattista Vico. Ithaca, N.Y.: Cornell University Press.

Berlin, I. (1977). Vico and Herder, two studies in the history of ideas. New York, N.Y.: Vintage Books.

Best, R. (1998). We've all got scars. Bloomington, I.N.: Indiana University Press.

Boorstin, D. J. (1983). The discoverers. New York, N.Y.: Random House.

Boorstin, D. J. (1992). The creators. New York, N.Y.: Random House.

Borg, W. (1987). Applying educational research. New York, N.Y.: Longman.

Borg, W., \& Gall, M. (1979). Educational research (3rd ed.). New York, N.Y.: Longman.

Bronowski, J. (1956). Science and human values. New York, N.Y.: Julian Messner.

Bronowski, J. (1973). The ascent of man. Boston, M.A.: Little, Brown \& Co..

Buchanan, M., \& Floden, R. E. (1989). Research traditions: Diversity and progress. Review of Educational Research, 59(2), 241-248.

Burt, C. (1966). The appropriate uses of factor analysis and analysis of variance. In R. B. Cattell (Ed.), Handbook of multivariate experimental psychology. Chicago, I.L.: Rand McNally.

Butterfield, H. (1957). The origins of modern science 1300-1800. New York, N.Y.: The Free Press.

Campbell, D. T., \& Stanley, J. C. (1963). Experimental and quasi-experimental designs for research. In N. L. Gage (Ed.), Handbook for research on teaching (pp. 171-246). Chicago, I.L.: Rand McNally.

Cattell, R. B. (1966). The meaning and strategic use of factor analysis. In R. B. Cattell (Ed.), Handbook of multivariate experimental psychology (pp. 174-243). Chicago, I.L.: Rand McNally.

Cromer, A. (1997). Connected knowledge, science, philosophy and education. New York, N.Y.: Oxford University Press.

Darwin, C. (1952). The origins of the species by means of natural selection. Chicago, I.L.: Encyclopedia Britannia.

Durant, W. A. (1961). The age of reason begins. New York, N.Y.: Simon \& Schuster.

Dyer, J. R. (1979). Understanding and evaluating educational research. Reading, M.A.: Addison-Wesley.

Einstein, A. (1945). The meaning of relativity. Princeton, N.J.: Princeton University Press. 
Eiseley, L. (1969). The unexpected universe. New York, N.Y.: Harcourt, Brace \& World.

Foskett, D. J. (1965). How to find out: Educational research. Oxford, U.K.: Pergamon Press.

Fraenkel, J. R., \& Wallen, N. E. (2000). How to design and evaluate research in education (4th ed.). New York, N.Y.: McGraw Hill.

Gage, N. L. (1996). Confronting counsels of despair for the behavioral sciences. Educational Researcher, 25(3), 5-15.

Galbraith, J. K. (1977). The age of uncertainty. Boston, M.A.: Houghton Mifflin.

Garfinkel, A. (1981). Forms of explanation, rethinking the questions in social theory. New Haven, C.N.: Yale University Press

Good, C. V. (1966). Essentials of educational research. New York, N.Y.: Appleton-Century Crofts.

Hawking, S. W. (1988). A brief history of time. New York, N.Y.: Bantam Books.

Hayman, J. L. (1968). Research in education. Columbus, O.H.: Charles Merrill Publishing Co..

Hillway, T. (1969). Handbook of educational research. Boston, M.A.: Houghton Mifflin.

Jacob, E. (1989). Qualitative research: A defense of traditions. Review of Educational Research, 59(2), 229-235.

Kaplan, A. (1964). The conduct of inquiry, methodology for behavioral science. San Francisco, C.A.: Chandler Publishing.

Kim, J. O., \& Mueller, C. W. (1978). Introduction to factor analysis, what it is and how to do it. Beverly Hills, C.A.: Sage Publications.

Kuhn, T. S. (1970). The structure of scientific revolutions (2nd ed.). Chicago, I.L.: University of Chicago Press.

Lagemann, E. C. (1997). Contested terrain: A history of education research in the United States, 1890-1990. Educational Researcher, 26(9), 5-17.

Mackeown, B., \& Thomas, D. (1988). Q methodology. Beverly Hills, C.A.: Sage Publications.

Mali, M. (1992). The rehabilitation of myth, Vico's "new science”. Cambridge, U.K.: Cambridge University Press.

Mill, J. S. (1987, 1872). The logic of the moral sciences. LaSalle, I.L.: Open Court Publishing.

Mishler, E. (1979). Meaning in context: Is there any other kind? Harvard Educational Review, 49, 1.

Peters, J. A. (1959). Classic papers in genetics. Englewood Cliffs, N.J.: Prentice-Hall.

Pompa, L. (1982). Vico, selected writings. Cambridge, U.K.: Cambridge University Press.

Sax, G. (1968). Empirical foundations of educational research. Englewood Cliffs, N.J.: Prentice-Hall.

Smith, G. M. (1962). A simplified guide to statistics for psychology and education. New York, N.Y.: Holt, Rinehart and Winston.

Sternberg, R. J. (1997). Thinking styles. Cambridge, U.K.: Cambridge University Press.

Tanner, D. (1998, January). The social consequences of bad research. Phi Delta Kappan, 79(5), 345-349.

Travers, R. N. W. (1969). An introduction to educational research. New York, N.Y.: Macmillan.

Watson, J. D. (1972). The double helix. New York, N.Y.: Atheneum.

Williams, C. T., \& Wolfe, G. K. (1979). Elements of research: A guide for writers. Sherman Oaks, C.A.: Alfred Publishing.

Williams, F. (1986). Reasoning with statistics, how to read quantitative research (3rd ed.). New York, N.Y.: Holt, Rinehart \& Winston.

Wilson, E. O. (1998a). Back from chaos. Atlantic Monthly, 281(3), 41-62.

Wilson, E. O. (1998b). Consilience: The unity of knowledge. New York, N.Y.: Knopf.

Wilson, E. O. (2014). A window on eternity: A biologist's walk through Gorongosa National Park. New York, N.Y.: Simon \& Schuster. 